\title{
FGFR2 NP_000132.3:p.K659E
}

National Cancer Institute

\section{Source}

National Cancer Institute. FGFR2 NP 000132.3:p.K659E. NCI Thesaurus. Code C107606.

A change in the amino acid residue at position 659 in the fibroblast growth factor receptor 2 protein where lysine has been replaced by glutamic acid. 